\title{
Effects of preheating temperature on the interfacial tensile strength for glass fiber reinforced polypropylene composites made by press and injection hybrid molding
}

\author{
K. Tanaka, R. Noguchi \& T. Katayama \\ Department of Biomedical Engineering, Doshisha University, Japan
}

\begin{abstract}
The use of glass fiber reinforced thermoplastic composites (GFRTP) is expected to contribute to weight reduction of automobiles. Traditional injection molding used for GFRTP can mold complex shapes. Because of the limitation of the fiber length and the unevenness of fiber distribution and orientation of molded products, however, injection molding is not suitable for the production of structural parts that require high mechanical properties. Although the thermoplastic composite laminates that use continuous fibers for reinforcement have excellent mechanical properties, it is difficult to mold complex shaped products such as ribs and bosses because of the limitation in formability of continuous fiber reinforced thermoplastics. Recently, to mold FRTP with excellent strength and stiffness that has complex shaped products with ribs and bosses, the hybrid molding process has been developed by combining press molding and injection molding. However, as its fracture occurs at the interface between the thermoplastic composite laminates and the rib, the interfacial strength should be improved. In this study, glass fiberreinforced polypropylene composites were molded by press and injection hybrid molding under different preheating temperatures of the thermoplastic composite laminates. The tensile tests using T-shaped specimens cut out from the molded products were performed to clarify the effect of the preheating temperature on the interfacial tensile strength. Higher interfacial tensile strength was obtained when the thermoplastic composite laminates were heated at high preheating temperature. Keywords: GFRP, injection molding, press molding, press and injection hybrid molding, preheating, interfacial strength.
\end{abstract}




\section{Introduction}

The use of fiber reinforced thermoplastic composite material (FRTP) is expected to contribute to weight reduction of automobiles because it has high specific strength and high specific rigidity, and can be recycle $[1,2]$. Since carbon fiberreinforced thermoplastic composites (CFRTP) are expensive [3], their application to mass-production automobiles is limited; in reality, the application of glass fiberreinforced thermoplastic composites (GFRTP) is expected.

Traditional injection molding used for GFRTP can mold complex shapes. Because of the limitation of the fiber length and the unevenness of fiber distribution and orientation of molded products, however, injection molding is not suitable for the production of structural parts that require high mechanical properties [4, 5]. Although the thermoplastic composite laminates that use continuous fibers for reinforcement have excellent mechanical properties, it is difficult to mold complex shaped products such as ribs and bosses because of the limitation in formability of continuous fiber reinforced thermoplastics [6].

Recently, to mold FRTP with excellent strength and stiffness that has complex shaped products with ribs and bosses, the hybrid molding process has been developed by combining press molding and injection molding [7]. However, it was reported that it fractures at the interface between the thermoplastic composite laminates and the rib [8-10]. The injection temperature was reported to affect the interfacial flexure strength of the thermoplastic composite laminates and the rib by conducting the flexural test of the hybrid molded structure [8]. We have reported that the higher interfacial tensile strength was obtained by using the thicker thermoplastic composite laminates because its temperature was kept due to the larger mass of the thermoplastic composite laminates [10]. Although the temperature of the thermoplastic composites laminates is important factor in the press and injection hybrid molding, however, the effect of preheating temperature that affects the temperature of the thermoplastic composite laminates on the interfacial tensile strength has not been clarified yet.

In this study, glass fiber-reinforced polypropylene composites were molded by press and injection hybrid molding under different preheating temperatures of the thermoplastic composite laminates. The tensile tests using T-shaped specimens cut out from the molded products were performed to clarify the effect of the preheating temperature on the interfacial tensile strength.

\section{Materials and experimental methods}

\subsection{Materials}

GF/PP sheets (NEOMATEX, KURABO Industries Ltd, $\mathrm{V}_{\mathrm{f}}=35 \%$, Thickness $=$ $0.5 \mathrm{~mm}$, Melting point $=154^{\circ} \mathrm{C}$ ) that consist of continuous glass fiber twill woven fabrics and polypropylene (PP) as matrix were used as the thermoplastic composite laminates. Four prepregs were stacked and press-molded at $210^{\circ} \mathrm{C}$ of molding temperature, $3 \mathrm{MPa}$ of pressure, and $360 \mathrm{~s}$ of holding time to be used for the outer layer materials of the press and injection hybrid molding. The 
polypropylene pellet (MA3, Japan Polypropylene Co. Ltd) was used for the materials of injection molding.

\subsection{Press and injection hybrid molding}

The schematic drawing of the press and injection hybrid molding process is shown in Fig. 1 and the molding condition is shown in Table 1. The thermoplastic composite laminates were heated and melted in advance using the heater at $200^{\circ} \mathrm{C}$, $230^{\circ} \mathrm{C}, 260^{\circ} \mathrm{C}$ and $290^{\circ} \mathrm{C}$ respectively; placed inside the mold held at $40^{\circ} \mathrm{C}$; and press-molded at $26 \mathrm{MPa}$. Then the molded products having the ribs as shown in Fig. 2 was molded by injection molding of $\mathrm{PP}$ at $210^{\circ} \mathrm{C}$. In the case that the thermoplastic composite laminates are preheated at $200^{\circ} \mathrm{C}$, the specimen is hereinafter referred to as P-20 as shown in Table 1. To understand the temperature histories of the thermoplastic composite laminates, the temperature of the surface, where the PP will be injected to form the ribs, was measured by using thermocouples as shown in Fig. 3. Temperature history was measured until the completion of injection molding.

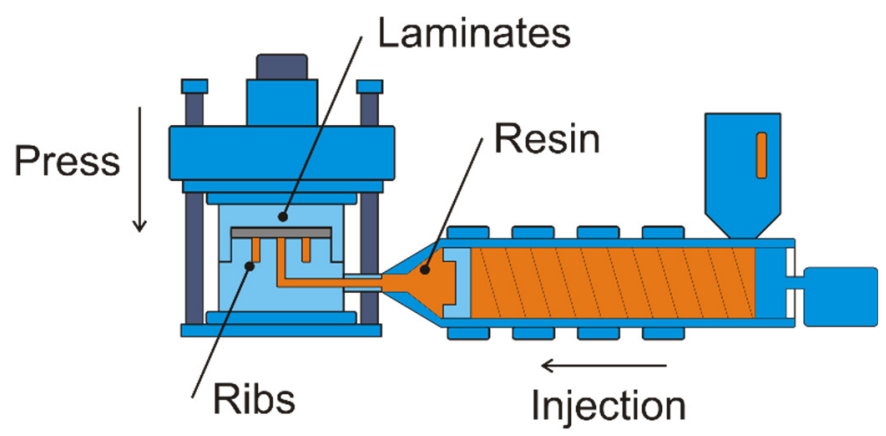

Figure 1: Schematic drawing of the press and injection hybrid molding process.

Table 1: Molding condition of the laminated composites.

\begin{tabular}{|c|c|c|c|c|}
\hline & $\begin{array}{c}\text { Preheating } \\
\text { temperature } \\
{\left[{ }^{\circ} \mathrm{C}\right]}\end{array}$ & $\begin{array}{c}\text { Preheating } \\
\text { time } \\
{[\mathrm{s}]}\end{array}$ & $\begin{array}{c}\text { Mold } \\
\text { temperature } \\
{\left[{ }^{\circ} \mathrm{C}\right]}\end{array}$ & $\begin{array}{c}\text { Injection } \\
\text { temperature } \\
{\left[{ }^{\circ} \mathrm{C}\right]}\end{array}$ \\
\cline { 1 - 2 } $\mathrm{P}-20$ & 200 & & & \\
\cline { 1 - 2 } $\mathrm{P}-23$ & 230 & 360 & 40 & 210 \\
\cline { 1 - 2 } $\mathrm{P}-26$ & 260 & & & \\
\hline $\mathrm{P}-29$ & 290 & & & \\
\hline
\end{tabular}




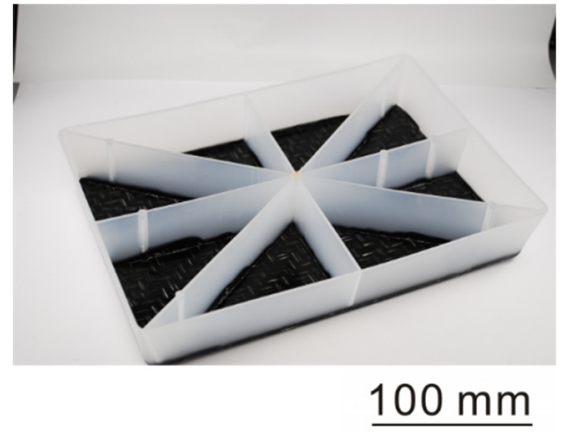

(a) Upper side (ribs structure)

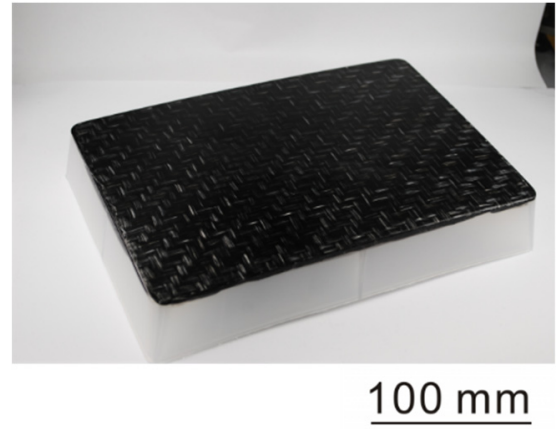

(b) Under side (laminates)

Figure 2: Molded product manufactured by the press and injection hybrid molding.

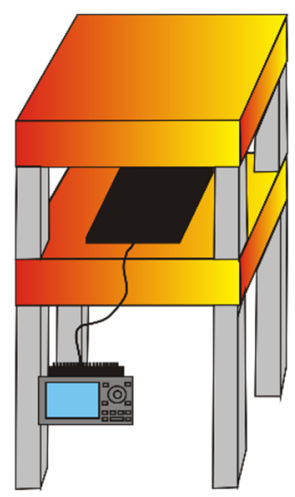

Preheating

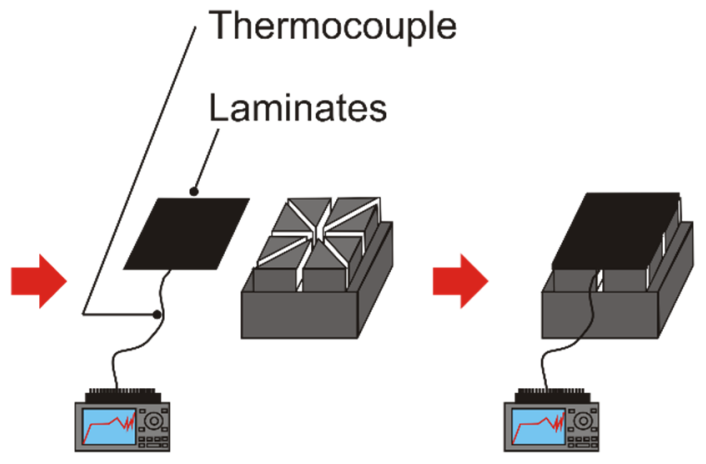

Transfer

Measured

Figure 3: Measurement of the temperature history for the thermoplastic composite laminates. 


\subsection{Mechanical testing}

In order to evaluate the interfacial tensile strength between the thermoplastic composite laminates and the ribs, T-shaped tensile tests were conducted with a cross head speed of $0.017 \mathrm{~mm} / \mathrm{sec}$ at room temperature with a universal material testing machine (5566, Instron) as shown in Fig. 4. T-shaped specimens were cut out from the molded products and aluminium tabs were bonded using epoxy adhesive. In this study, the interfacial tensile strength was calculated by dividing the maximum fracture loads during the T-shaped tensile tests by the crosssectional area of the interface. Optical 3D deformation analysis system (ARAMIS, $\mathrm{GOMmbH}$ ) was used for the strain measurement of the T-shaped test specimens.
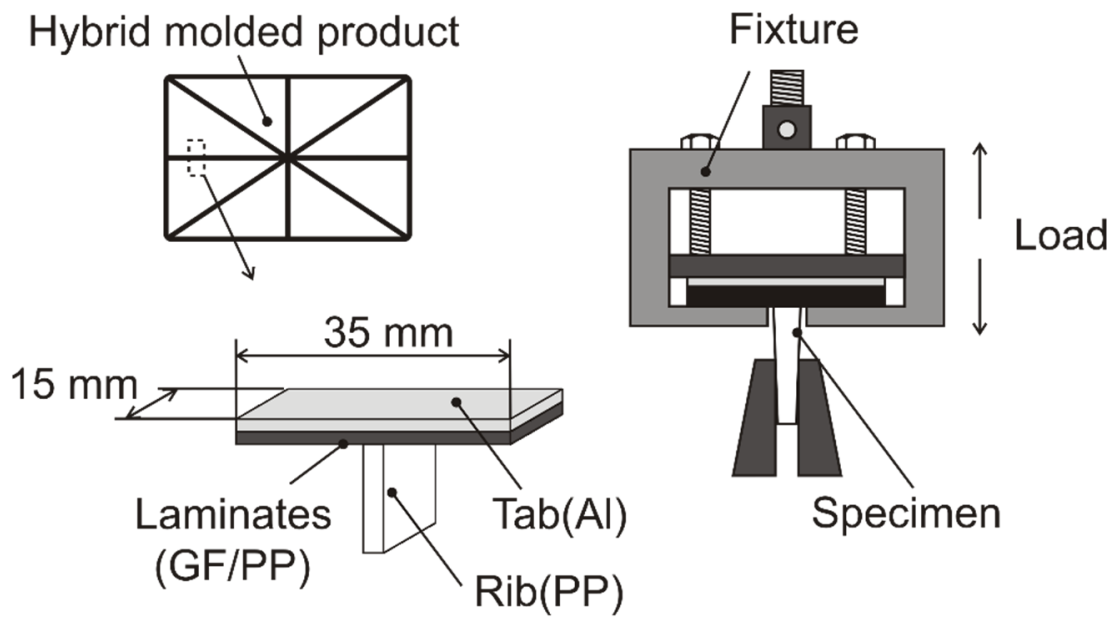

Figure 4: Schematic drawing of T shaped specimen and tensile test.

\section{Results and discussion}

\subsection{Temperature history}

The temperature history of the thermoplastic composite laminates of the surface is shown in Fig. 5. Although the temperatures of the thermoplastic composite laminates of P-20 and P-23 were below the melting point of PP at the completion of injection, those of P-26 and P-29 were higher than the melting point. 


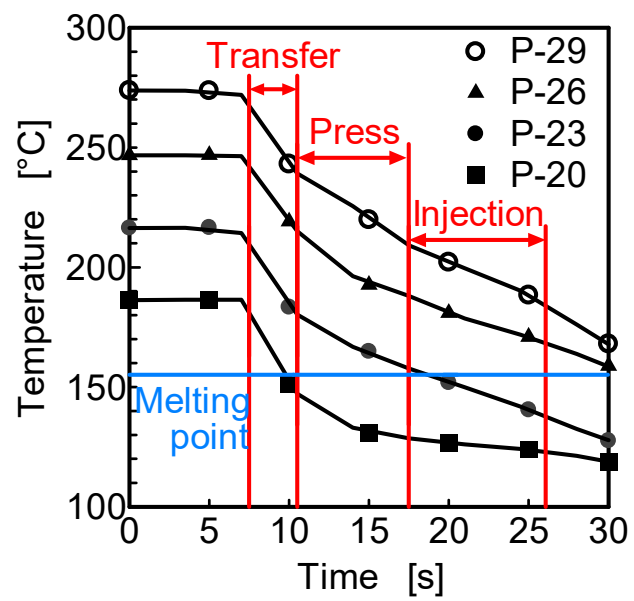

Figure 5: Temperature histories of the thermoplastic composite laminates for different preheating temperature.

\subsection{Interfacial tensile strength between the thermoplastic composite laminates and the rib}

The cross-sectional views of T-shaped test specimens for P-20 and P-26 are shown in Fig. 6. Whereas clear interface between the thermoplastic composite laminates and the rib was observed on P-20, it was not clearly observed on P-26. The interfacial tensile strength of the $\mathrm{T}$-shaped specimen molded at different preheating temperature is shown in Fig. 7. The interfacial tensile strengths of P-20, P-23, P-26, and P-29 are 10.3MPa, 13.4MPa, 16.9MPa, and $17.1 \mathrm{MPa}$ respectively. P-26 shows a value that is approximately $69 \%$ higher than $\mathrm{P}-20$, and approximately $27 \%$ higher than $\mathrm{P}-23$. However, there is no significant difference in value between P-26 and P-29.

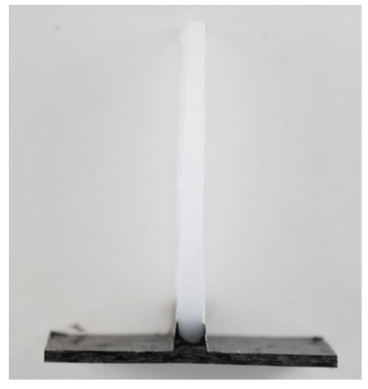

(a) P-20

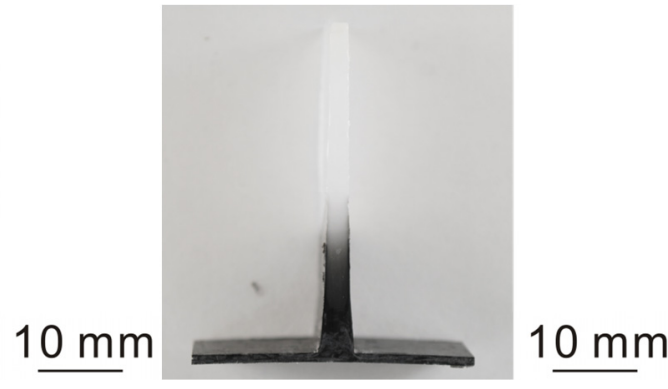

(b) P-26

Figure 6: Cross-sectional views for T-shaped test specimens for P-20 and P-26. 


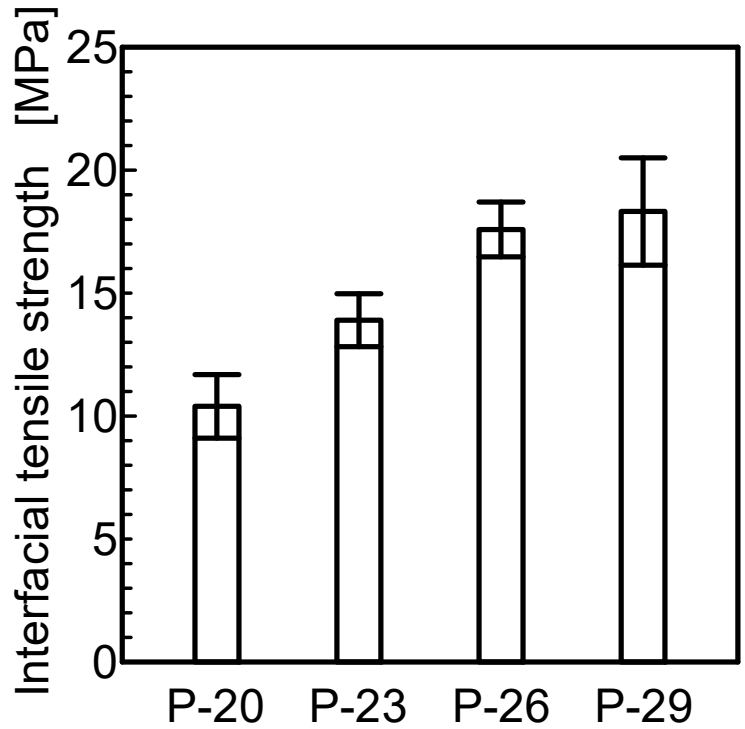

Figure 7: The interfacial tensile strength for T-shaped tensile tests for different preheating temperatures.

Figure 8 shows the strain distribution of P-20 and P-26 when $\varepsilon=0.5$, just before the final fracture of the P-20 specimen. The stress concentration of the interface of P-20 between the thermoplastic composite laminates and the rib was more remarkable than that of P-26. Fig. 9 shows the strain distribution of P-26 when $\varepsilon=1.1$, just before the final fracture of P-26 specimen. The stress concentration of the interface of P-26 between the thermoplastic composite laminates and the rib was similarly observed. The stress concentration on the interface of P-26 was observed at larger strain than that of P-20. Side views and fracture surfaces of P-20 and P-26 are shown in Fig. 10. For P-20, fracture occurred at the interface between the thermoplastic composite laminates and the rib and injected material of PP was not observed on the fracture surface. On the other hand, for P-26, fracture occurred near the interface and injected material of PP was observed on the fracture surface.

As shown in Fig. 5, the temperature of the thermoplastic composite laminates of P-26 was higher than the melting point. Therefore the interfacial tensile strength between the thermoplastic composite laminate and injected material was increased and fracture occurred mainly in the injected materials. 


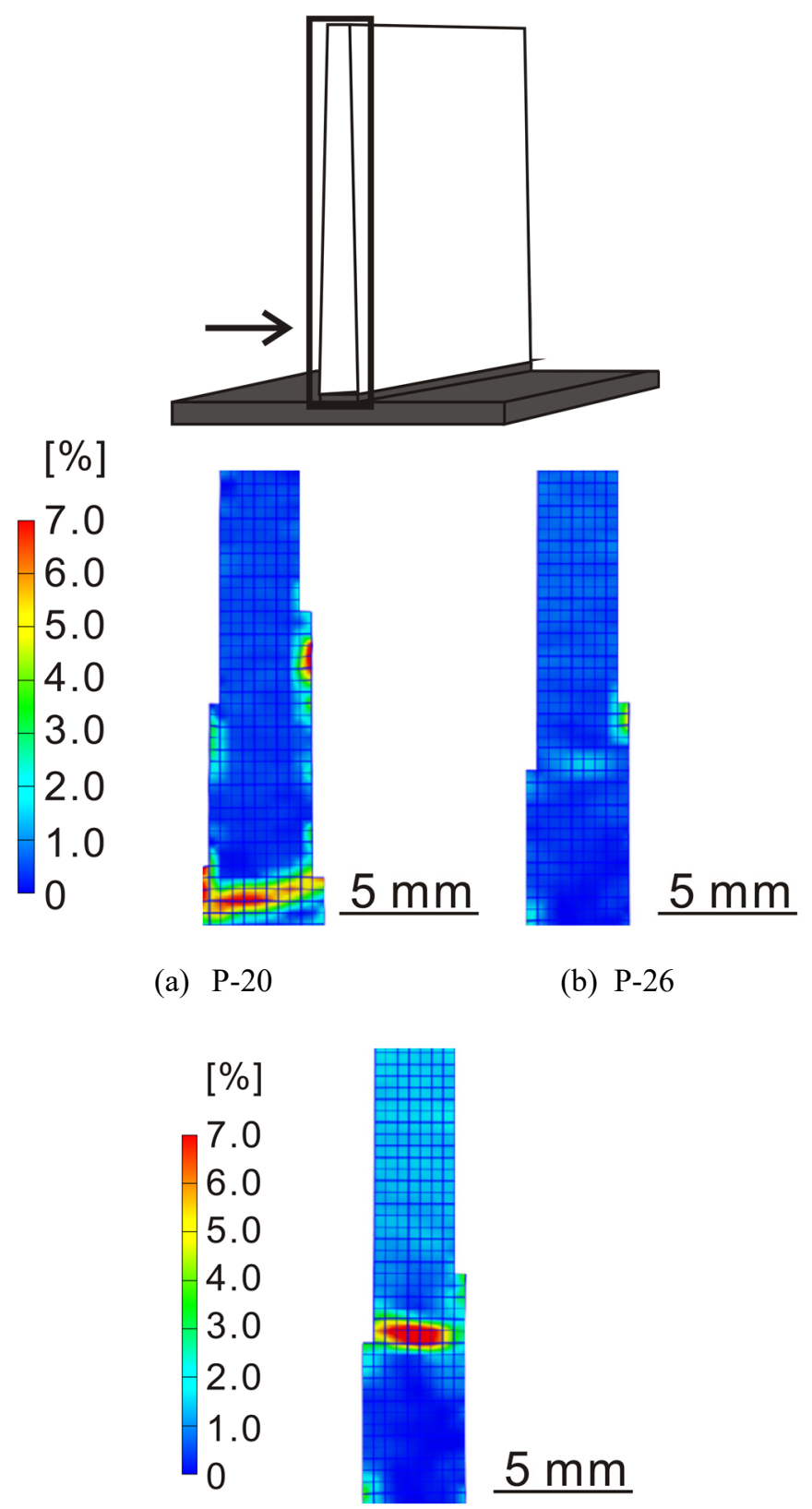

Figure 8: $\quad$ Strain distribution for P-26 $(\varepsilon=1.1)$. 


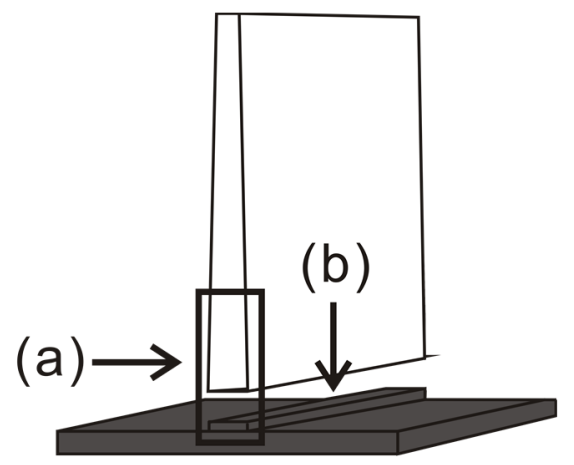

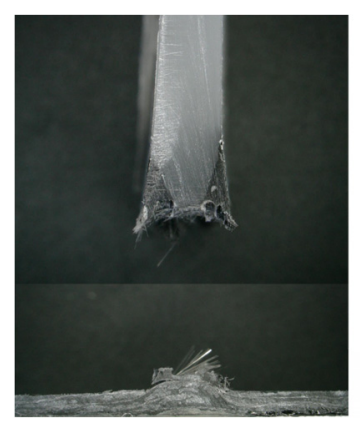

(a) Side view

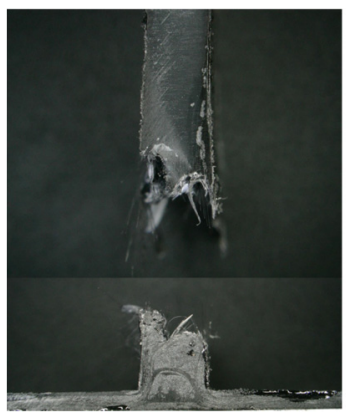

(a) Side view

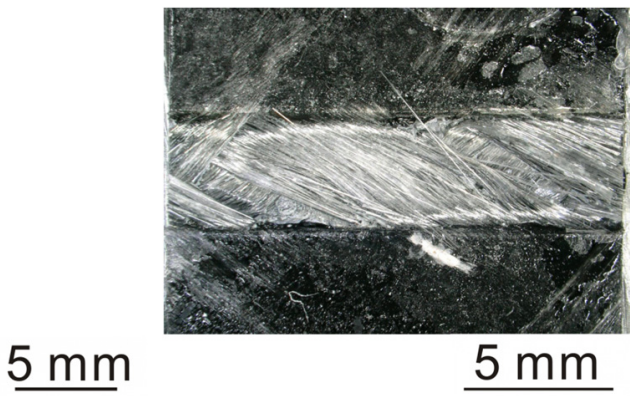

(b) Fractured surface

(i) $\mathrm{P}-20$

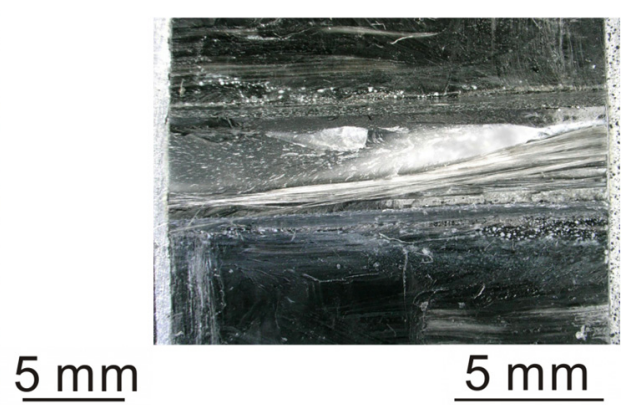

(b) Fractured surface

(ii) $\mathrm{P}-26$

Figure 9: Side views and fracture surfaces of T-shaped specimens.

\section{Conclusion}

Glass fiber-reinforced polypropylene composites were molded by press and injection hybrid molding under different preheating temperatures of the 
thermoplastic composite laminates. The tensile tests using T-shaped specimens cut out from the products were performed to clarify the effect of the preheating temperature on the interfacial tensile strength. The investigation yielded the following conclusions:

1. Higher interfacial tensile strength between the thermoplastic composite laminates and the ribs is obtained when the temperature of the thermoplastic composite laminates is kept above the melting point of polypropylene until the completion of the injection process.

2. During the tensile tests of T-shaped specimens, the stress concentration of the interface between the thermoplastic composite laminates and the rib was observed. When the thermoplastic composite laminate is heated and molded at high preheating temperatures, a fracture occurred near the interface and injected material of PP was observed on the fracture surface.

\section{References}

[1] Mallick, P. K., Fiber-reinforced Composites: Materials Manufacturing and Design, CRC Press, p. 2, 2007.

[2] Uzawa, K., Present and Future State of FRP Processing, Journal of the Society of Materials Science, Vol. 55, No. 1, pp. 131-137, 2006.

[3] Michael, F. A., Material Selection in Mechanical Design, ButterworthHeinemann, pp. 482-483, 2011.

[4] Ogawa, T., Mima, M., Taya, N., Change of Fiber Length in Injection Molding of Carbon Fiber Reinforced Nylon 66, Seikei-Kakou, Vol. 7, No. 5, pp. 315-320, 1995.

[5] Watanabe, T., Fujii, T., Long fiber effect on static and fatigue strengths of discontinuous fiber reinforced thermoplastics with polypropylene matrix, The Japan Society of Mechanical Engineers, Vol. 64, No. 623, pp. 224-231, 1998.

[6] Zhu, B., Yu, T.X., Zhang, H., Tao, X. M., Experimental investigation of formability of woven textile composite preform in stamping operation, International Journal of Material Forming, Vol. 1, No. 1, pp. 969-972, 2008.

[7] Harte, A. M., Namara, J. F. Mc., Overinjection of thermoplastic composites, Journal of Materials Processing Technology, Vol. 182, No. 1-3, pp. 12-20, 2007.

[8] Fiorotto, M., Lucchetta, G., Experimental investigation of a new hybrid molding process to manufacture high-performance composites, International Journal Material Forming, Vol. 6, No. 1, pp. 179-185, 2013.

[9] Asanuma, N., Applying Direct Injection Molding Process and Hybrid Molding System to CFRP Molding, Journal of the Japan Society of Polymer Processing, Vol. 27, pp. 89-93, 2015.

[10] Tanaka, K., Fujita, Y., Katayama, T., Press and Injection Hybrid Molding of Glass Fiber Reinforced Thermoplastics, WIT Transactions on Engineering Sciences, Vol. 90, No. 7, pp. 225-232, 2015. 